\title{
A Design of LED Digital Tube Intelligent Alarm Clock Based on MCU
}

\author{
Xijia Feng \\ School of Information and Electrical Engineering, \\ Harbin Institute of Technology at Weihai, \\ Weihai 264209, China \\ Email:1326249116@qq.com
}

\begin{abstract}
In order to make up for some shortcomings in the alarm clock based on smart phones, a design of LED digital tube intelligent alarm clock based on MCU is proposed. The project: LED digital tube intelligent alarm clock is based on MCU, which consists of the STC90C516RD MCU, together with some peripherals packaging on the development board. The software part is based on the platform Keil $\mu v i s o n$ 4, the programs of which consist of functions which can achieve several specific functions. The expected time will be displayed on 8 digital tubes; the alarm time will be set so long as the source program is compiled. As soon as the LED digital tube intelligent alarm clock goes off, the system time will be displayed on the digital tubes while the buzzer will alarm at a frequency of 1000 $\mathrm{Hz}$ until the button of the independent keyboard unit is pressed. The hardware part of this subject is suitable and the software design which had been tested during the experiments is proved to be executable.
\end{abstract}

Keywords-MCU; digital tube; intelligent alarm clock; interrupt; function

\section{INTRODUCTION}

Intelligent alarm clock is quite a common electronic device among consumers. Almost every citizens use the intelligent alarm clock to wake up themselves every day, they set time in the intelligent alarm clock so that it could warn them at the setting time ${ }^{[1]}$. Mechanical alarm clocks were used by everyone in the past, but it applied mechanical devices to set hour and minute ${ }^{[2]}$; it is not an "intelligent" alarm clock. Now almost all intelligent alarm clocks are designed in smart mobile phone ${ }^{[3]}$, they are APPs in smart mobile phone; they are not free-running product for alarm clock ${ }^{[4]}$. On the one hand, the smart mobile phone is belong to the user himself, as a result, the intelligent alarm clock in smart mobile phone couldn't be displayed for all members in certain places such as dormitory etc. On the other hand, the alarm clock is usually delicate in appearance, therefore, it can also be used for decoration while the smart phones can only be carried with users. To correct these shortcomings of intelligent alarm clock in smart mobile phone, we has designed a LED digital tube intelligent alarm clock based on MCU. The LED digital tube intelligent alarm clock is a free-running product for alarm clock, the control core of which is the STC90C516RD MCU ${ }^{[5,6]}$, it can display time and alarm on setting time; the LED digital tube intelligent alarm clock based on MCU can be places on tables or furniture and used for everyone, Thus, the shortcomings of the intelligent

This paper was supported by the freshmen' science and technology innovation project of Harbin Institute of Technology at Weihai. alarm clock based on smart mobile phones have been corrected and the product is proved to be very useful.

\section{THE HARDWARE DESIGN OF LED DIGITAL TUBE INTELLIGENT ALARM CLOCK BASED ON MCU}

\section{A. The design of MCU circuit board}

The LED digital tube intelligent alarm clock needs many circuit units and I/O devices, the circuit units are MCU socket circuit unit, reset circuit unit, clock circuit unit, memory circuit unit and interrupting circuit unit, the I/O devices are LED digital tube unit, independent keyboard unit, array keyboard unit and buzzer unit. It is impossible to design these circuit units and devices by welding components and linking wires, so integrating these circuit units and $\mathrm{I} / \mathrm{O}$ devices into a circuit board is necessary. A MCU circuit board marked HC6800 EM3 -V2.2 integrated these circuit units and I/O devices, so the MCU circuit board was designed as main circuit body of the LED digital tube intelligent alarm clock based on MCU. The MCU circuit board marked HC6800 EM3-V2.2 was produced by Shenzhen PRECHIN Co. Ltd, among it, there were a MCU socket circuit unit placing $8052 \mathrm{MCU}$, a set of reset circuit unit, a clock circuit unit, two memory circuit units and five interrupting circuit units, there were 9 LED digital tube unit, an independent keyboard unit, an array keyboard unit and an buzzer unit on the MCU circuit board, it is a ideal MCU circuit board for the design of LED digital tube intelligent alarm clock based on MCU.

\section{B. The main hardware modules of the design}

According to the expected hardware functions, the main hardware modules of the design of LED digital tube intelligent alarm clock based on MCU consist of four hardware modules: main control module, display module, alarm module and interrupting module.

\section{1) The main control module}

The core of main control module is the STC90C516RD MCU, attaching reset circuit unit and clock circuit unit. The STC90C516RD MCU is a very powerful MCU, provides the following standard features: $8 \mathrm{~K}$ bytes of Flash, 256 bytes of RAM, 32 I/O lines, watchdog timer, two data pointers, three 16-bit timer/counters, a six-vector two-level interrupt architecture, a full duplex serial port. The reset circuit unit has made it possible for user programs runs from 0 address 
instruction when reset button was pressed. The clock circuit unit provides $12 \mathrm{MHz}$ clock for circuit system. The main control module was the most important hardware in LED digital tube intelligent alarm clock based on $\mathrm{MCU}$, it runs user's programs and processes I/O data, enables the LED digital tube intelligent alarm clock to work well.

\section{2) The display module}

The display module is made of 8 digital tubes, the 8 digital tubes are common cathode by 8 pullups, their data bus connect P0 port of The STC90C516RD MCU. Each digital tube consists of 7 LEDs, when P0 port outputs a display code, one of the 8 digital tubes displays a char relating the display code. The display form is hour-minute-second, and 8 digital tubes are necessary; thus, the mode of the display module is dynamic display. The 74LS138 decoder is applied to select 8 digital tubes, pin A, pin B, pin C of the 74LS138 connected P2.0 pin, $\mathrm{P} 2.1$ pin, $\mathrm{P} 2.2$ pin of the $\mathrm{P} 2$ port.

\section{3 ) The alarm module}

The alarm module is made of a passive buzzer and a power amplifier circuit, the passive buzzer can react all signals as long as the frequency lays from $20 \mathrm{~Hz}$ to $20000 \mathrm{~Hz}$, which the sound that the alarm module output is available for human beings; the main body of the power amplifier circuit is a PNP transistor, the power amplifier circuit amplifies the alarm signal from P3.7 pin of the P3 port. In the LED digital tube intelligent alarm clock, the frequency of the alarm sound is $1000 \mathrm{~Hz}$, the sound is enough for waking up sleeping people.

\section{4) The interrupting module}

The function of the interrupting module is to stop the alarm sound and always display the setting time in the LED digital tubes, the request of interrupting is emitted by independent keyboard unit, the pin of independent keyboard unit connected P3.3 of the P3 port, when the button of independent keyboard unit is pressed, the external interrupting mode 1 is transported to MCU by P3.3 of the P3 port, the MCU will acknowledge the external interrupting mode 1 and run interrupting programs.

\section{THE SOFTWARE DESIGN OF LED DIGITAL TUBE INTELLIGENT ALARM CLOCK BASED ON MCU}

The software design includes editing source program, compiling source program, downloading *.exe files; the development tools is the Keil uvison 4 and the PZ-ISP. The source program was edited and compiled in the Keil $\mu$ vison 4, and the *.exe file is downloaded in the PZ-ISP. The source program includes a head file, two macro defines, a display code arrays, a digital tubes selecting arrays, a system time macro arrays, a setting time arrays, a delaying function, a main function, a sound function and two interrupting functions; the source program is shown below.

\#include $<$ reg52.h $>$

\#define uint unsigned int

\#define uchar unsigned char

sbit fmq $=\mathrm{P}^{\wedge}{ }^{\wedge}$;

uchar i;

uchar code shuzu[] $=\{0 \times 3 f, 0 \times 06,0 \times 5 b, 0 \times 4 f, 0 \times 66$,

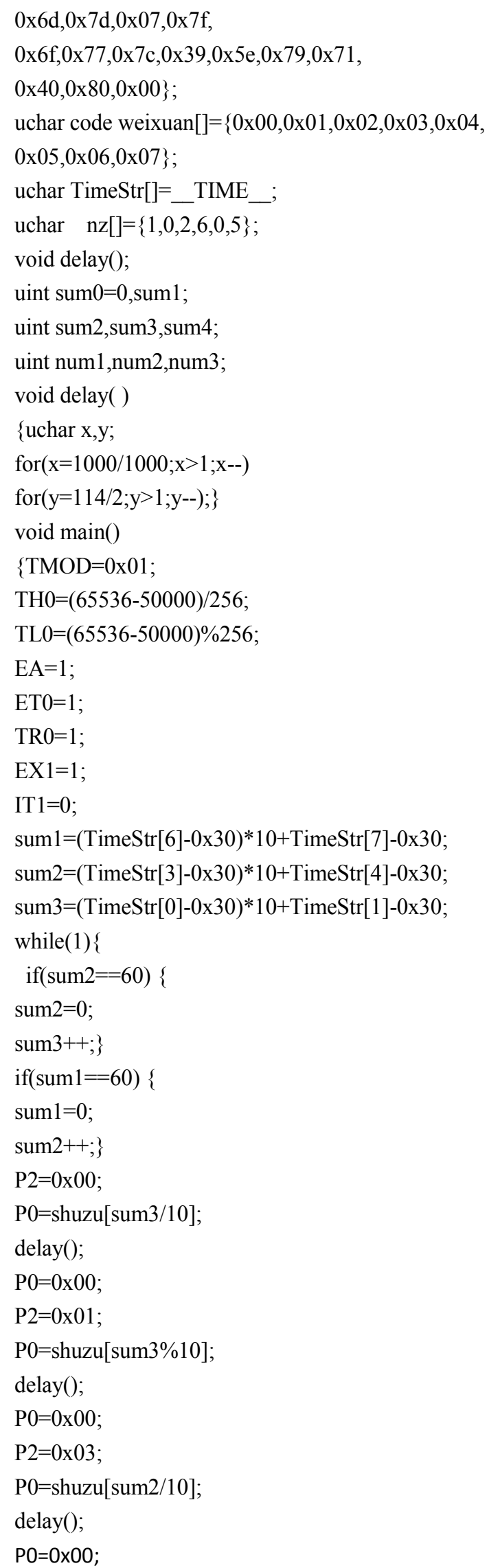


$\mathrm{P} 2=0 \mathrm{x} 04$

$\mathrm{P} 0=$ shuzu[sum $2 \% 10]$;

delay();

$\mathrm{P} 0=0 \mathrm{x} 00$;

$\mathrm{P} 2=0 \mathrm{x} 06$;

$\mathrm{P} 0=$ shuzu[sum $1 / 10]$;

$\operatorname{delay}()$;

$\mathrm{P} 0=0 \mathrm{x} 00$;

$\mathrm{P} 2=0 \times 07$

$\mathrm{P} 0=$ shuzu[sum $1 \% 10]$;

delay();

$\mathrm{P} 0=0 \mathrm{x} 00$;

sum $4=((\mathrm{nz}[0] * 10+\mathrm{nz}[1])-\operatorname{sum} 3) * 3600$

$+((\mathrm{nz}[2] * 10+\mathrm{nz}[3])-\mathrm{sum} 2) * 60+$

$(\mathrm{nz}[4] * 10+\mathrm{nz}[5])-\mathrm{sum} 1$;

if(sum4==0)

num1=sum 1 ; num 2=sum 2 ;

num3=sum3;

while(1) \{

fmq $=0$; delay () ;

fmq $=1$; delay () ;

$\mathrm{P} 2=0 \mathrm{x} 00$;

$\mathrm{P} 0=$ shuzu[num3/10];

delay();

$\mathrm{P} 0=0 \mathrm{x} 00$;

$\mathrm{P} 2=0 \mathrm{x} 01 ;$

$\mathrm{P} 0=$ shuzu[num3\%10];

delay();

$\mathrm{P} 0=0 \mathrm{x} 00$;

$\mathrm{P} 2=0 \times 03$;

$\mathrm{P} 0=$ shuzu[num2/10];

delay();

$\mathrm{P} 0=0 \mathrm{x} 00$;

$\mathrm{P} 2=0 \mathrm{x} 04$;

$\mathrm{P} 0=$ shuzu[num $2 \% 10]$;

delay();

$\mathrm{P} 0=0 \mathrm{x} 00$;

$\mathrm{P} 2=0 \times 06$;

$\mathrm{P} 0=$ shuzu[num1/10];

delay();

$\mathrm{P} 0=0 \mathrm{x} 00$;

$\mathrm{P} 2=0 \mathrm{x} 07$;

$\mathrm{P} 0=$ shuzu[num $1 \% 10]$;

delay();

$\mathrm{P} 0=0 \times 00 ;\}\}$ \}

void intt0() interrupt 1\{
$\mathrm{TH}=(65536-50000) / 256$;

$\mathrm{TL} 0=(65536-50000) \% 256$;

sum0++;

if $(\operatorname{sum} 0==20)\{$

sum $0=0$;

sum1++;

sum4--;\} \}

void ext1() interrupt 2\{

while(1)\{

$\mathrm{P} 2=0 \mathrm{x} 00$;

$\mathrm{P} 0=$ shuzu[num3/10];

delay();

$\mathrm{P} 0=0 \mathrm{x} 00$;

$\mathrm{P} 2=0 \times 01$;

$\mathrm{P} 0=$ shuzu[num3\%10];

$\operatorname{delay}() ;$

$\mathrm{P} 0=0 \mathrm{x} 00$;

$\mathrm{P} 2=0 \mathrm{x} 03$;

$\mathrm{P} 0=$ shuzu[num $2 / 10]$;

delay();

$\mathrm{P} 0=0 \mathrm{x} 00$;

$\mathrm{P} 2=0 \mathrm{x} 04$;

$\mathrm{P} 0=$ shuzu[num $2 \% 10]$;

delay();

$\mathrm{P} 0=0 \mathrm{x} 00$;

$\mathrm{P} 2=0 \times 06$;

$\mathrm{P} 0=$ shuzu[num1/10];

delay();

$\mathrm{P} 0=0 \mathrm{x} 00$;

$\mathrm{P} 2=0 \mathrm{x} 07$;

$\mathrm{P} 0=$ shuzu[num $1 \% 10]$;

delay();

$\mathrm{P} 0=0 \mathrm{x} 00$;

fmq $=1 ;\}\}\}$

IV. THE RESUlt OF THE DESIGN OF LED DigitAL TUBE INTELLIGENT ALARM CLOCK BASED ON MCU

Following the design of hardware and the design of software, the 8 digital tubes are connected to P0 port of The STC90C516RD MCU, the passive buzzer is connected to P3.7 of the P3 port, the pin of independent keyboard unit is connected to P3.3 of the P3 port, the setting time is $22: 24: 24$. When 22:23:00 comes, the users should compile the source program in order to create a *hex file. Meanwhile, the *.exe file will have been downloaded in the PZ-ISP to MCU circuit board. After that, the 8 digital tubes displays the system time from "22 23 00"; in 1 minute and 24 seconds, the buzzer will 
alarm, the 8 digital tubes displays "22 $24 \quad 24$ " invariably; after the button of independent keyboard unit being pressed, the the buzzer will stop alarming. The result of the LED digital tube intelligent alarm clock based on MCU is shown on figure 1 .

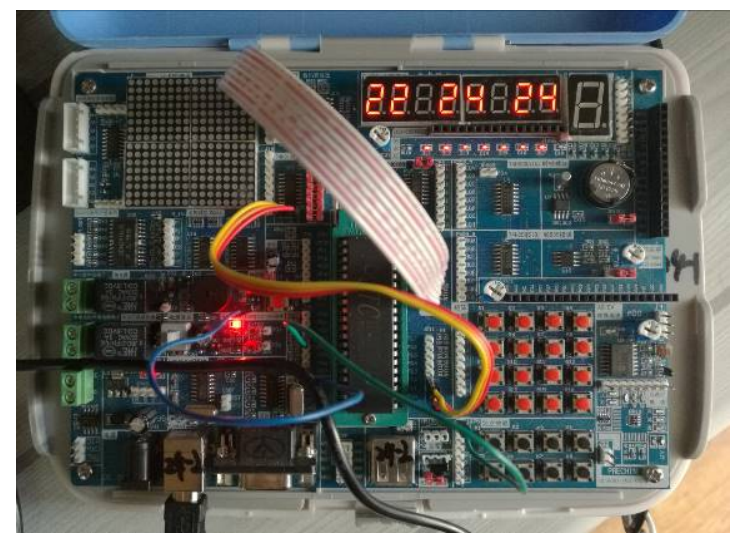

Fig.1 The result of the design

\section{CONCLUSION}

It is concluded that any design based on MCU must be included the hardware design and software design. In the hardware design, we tested how to select one of these digital tubes, the books about MCU provided many ways such as logic circuits selecting or gating circuits, but those ways proved to be no avail. We found that the 74LS138 decode was the best way how to select one of 8 the 8 digital tubes. In the software design, we finally came to a conclusion that decreasing the delaying time could avoid the problem of flashing among the 8 digital tubes, increasing the cycle of the buzzer could improve the sound of it. On compiling stage, we should set the time 15 seconds ahead of the system time in order to make time for compiling. In following months, we plan to display the time and date on the $1602 \mathrm{LCD}$ and use the array keyboard unit to change the alarm time.

\section{ACKNOWLEDGMENTS}

This paper was supported by the freshmen' science and technology innovation project of Harbin Institute of Technology at Weihai.

\section{REFERENCES}

[1] Landry B M, Pierce J S. Supporting routine decision-making with a next-generation alarm clock[J]. Personal and Ubiquitous Computing, 2004, 8(3):154-160

[2] Scott G, Chin J. A DIY approach to pervasive computing for the Internet of Things: A smart alarm clock[C]// Computer Science and Electronic Engineering Conference. IEEE, 2013:57-60.

[3] Acharjee D, Mukherjee A, Mandal J K, et al. Activity recognition system using inbuilt sensors of smart mobile phone and minimizing feature vectors[J]. Microsystem Technologies, 2015:1-8.

[4] Lee J I, Chang I, Pradhan A S, et al. On the use of new generation mobile phone (smart phone) for retrospective accident dosimetry[J]. Radiation Physics \& Chemistry, 2015, 116:151-154.

[5] Acharjee D, Maity S P, Mukherjee A. Hidden Markov model a tool for recognition of human contexts using sensors of smart mobile phone[J]. Microsystem Technologies, 2017, 23(3):571-582.

[6] Zhang Y, Liu H, Su X, et al. Remote Mobile Health Monitoring System Based on Smart Phone and Browser/Server Structure.[J]. Journal of Healthcare Engineering, 2015, 6(4):717-738. 